\title{
The challenge of making nudging attractive to politicians
}

\author{
GUS O'DONNELL
}

Frontier Economics, London, UK

\begin{abstract}
This article discusses some of the political barriers to the adaption of behavioural approaches to public policy. It contrasts the increasing acceptance of behavioural ideas in the civil service with the limited enthusiasm displayed, so far, by politicians. It also suggests that more attention should be focused on the impact of those affected by behavioural initiatives.
\end{abstract}

Submitted 12 December 2017; revised 27 February 2018; accepted 13 March 2018

The article by Sanders et al. (2018) tells the story of what has been learned during the early years of the existence of the UK Behavioural Insights Team, otherwise known as the Nudge Unit. As someone heavily involved in setting up the unit and still a strong supporter of the team, I am far from a disinterested commentator. However, I recommend anyone considering behavioural approaches to policy issues to read this article carefully.

It is very easy for what appear to be clever nudges to have less effect than you would like. My own take on the scaling-up problem is slightly different to theirs. Take the tax letter example: for me, the tragedy was that we didn't manage to get all departments, including all of Her Majesty's Revenue and Customs (HMRC), the UK tax authority, to realise that they needed a fundamental change in the way they communicated with the public. In particular, many of the civil servants writing the letters were not incentivised, or even encouraged, to work out what outcome the communication was trying to achieve and then come up with a way or ways that could be tested in order to get the best outcome. Instead, the incentives were to draft an accurate letter that could not be criticised by Select Committees or lobby groups. 
The authors also explore some of my early worries about nudges: would they wear off? Would they bring government into disrepute as a 'hidden persuader' or, even worse, a nanny telling the public what was really in its own interest? In this respect, it is interesting that some regulatory shoves, like no smoking in pubs, have become accepted very quickly, even by smokers. The shove has opened up a new possibility - pubs uncontaminated by smoke - that an unexpectedly high number of people find pleasant. This opens up a whole new area of controversy: should governments adopt regulations that ex ante are not wanted but ex post are welcomed? Raw politics suggests implementing such schemes if the change in views comes before the next election. Just as the received wisdom is that governments should implement unpopular measures like tax increases early on in their lives, so it might make sense to implement behavioural initiatives early as well if you expect them to be welcomed after a lag.

My worry that moving the Behavioural Insights Team out of government might lead to a decline in its influence has not been realised: indeed, the globalisation of the unit has helped to demonstrate the importance of behavioural approaches around the world and provided lots of examples from different cultures. The nudge team has had a profound effect on the British Civil Service: now all policy professionals are taught how to use behavioural techniques. The authors describe this process as a battle to break "economists' intellectual hegemony over government." This is not how I see it - but again, I should own up to my own potential biases as a former head of the Government Economic Service. The economists took over from generalists as the era of government by gifted amateurs came to an end. But their influence stemmed in large part from their desire to provide clear answers to difficult policy questions.

The problem lies above: there are very few serious politicians who are championing behavioural approaches. Indeed, in our parliamentary democracy, politicians are often judged by their peers in terms of how they perform in parliament. Such performances are associated with passing legislation, so there is a bias towards legislative solutions. In a world that is changing rapidly and with rapidly evolving behaviour patterns, legislation is a very blunt, inflexible tool. I hope the Behavioural Insights Team's self-funded study on behavioural government comes to grips with biases of this kind.

One possible explanation is that national politicians are put off by behavioural approaches because they are worried that voters will think they are being patronised. Another reason is that politicians are unlikely to gain personal credit as a result of successful nudges: the subtlety of nudges is a real problem. In my experience, politicians from the right worry about the nanny state/patronising criticism, while those from the left want more visible action 
by the government to show that the politician understands the problem and is dealing with it.

It is also difficult to get politicians to accept proper testing of potential solutions. Some argue that they cannot defend to their constituents treating some differently from others as happens in randomised controlled trials. Others are simply impatient and not prepared to await the outcome of trials. It would be interesting to know if this problem is worse in countries like New Zealand with elections every three years compared to those with longer terms.

In contrast, politicians at the local level seem much more interested in behavioural approaches. This is also true of charities and bodies representing civil society. Here, there is a different problem: namely that of scale. Many charities love the idea of testing different approaches and coming up with smart, significant findings. However, many of these bodies deal with small groups of clients, making randomised controlled trials useless. The behavioural community needs to find ways to help these smaller organisations to innovate while accepting that measuring success will be difficult.

I would also emphasise the need to understand nudges that can have really important effects and those that produce significant results but are of second-order importance. For example, the default switch in pensions has saved billions of pounds if compared to the alternative of greater tax reliefs. The tax letter has brought forward tens of millions of revenue, so is clearly of a completely different scale. Leaders of nudge units need to ensure that most resources are devoted to the 'big' challenges and are not spread too thinly to make a real difference. This will also lead to more research into how to measure the success of nudges. It is fairly simple to work out how much extra revenue has come in when a new letter is used. But what of a nudge that encourages more people to volunteer in hospitals to improve patient care? Many of the gains are in the form of increasing the well-being of the staff, the patients and the volunteers. This is why I believe more research into how to measure the impact on well-being is badly needed and should really have preceded the dash to behavioural approaches. We also need to be aware of the impact of policies on the distribution of well-being: gains to those with very low levels are clearly more valuable than similar-sized gains to those who are already very content with their lives. Nudges are likely to have distributional effects and these effects need to be explained to the key decision-makers.

Sanders et al. (2018) point out the problem of unintended consequences. This is a real fear. If, by auto-enrolment, we end up with a generation who have never thought about pensions, we might find they use their new freedoms to draw down pensions in ways that they might later regret. This is not an argument against auto-enrolment, but a plea for appropriate help to be provided when important financial decisions are made. Similarly, nudges for repeated 
decisions may be unnecessary, as individuals may learn from past mistakes. The analyst has to consider whether this learning is sufficient to offset the costs incurred as a result of past mistakes, building in gains from the individual learning that might be useful in many other areas.

Finally, in the UK, we have a once-in-a-lifetime opportunity to explore greater use of behavioural approaches because of Brexit. The legislation working its way through parliament basically writes all of the last 40 years of EU regulations into UK law. There is an opportunity to see if behavioural approaches might be superior to these regulations. Obviously, the extent of this opportunity will depend upon the UK's ability and desire to deviate from EU rules, as this may create problems for market access.

In conclusion, I believe there is plenty of scope for heads of agencies, trusts and third-sector organisations to explore behavioural approaches. At the central government level, the UK Civil Service and many others are keen to try out these new ideas. The big task is to convince politicians that these approaches will help them create a better world for their constituents and improve their standing with their electorate.

\section{Reference}

Sanders, M., V. Snijders and M. Hallsworth (2018), 'Behavioural science and policy: where are we now and where are we going?’ Behavioural Public Policy, 2(2): 144-167. 